Chapter 9

Design of Modular Reconfigurable MicroAssembly Systems 


\title{
STRATEGIES AND DEVICES FOR A MODULAR DESKTOP FACTORY
}

\author{
Arne Burisch, Annika Raatz, Jürgen Hesselbach \\ Technical University Braunschweig \\ Institute of Machine Tools and Production Technology (IWF) \\ Langer Kamp 19b, 38100 Braunschweig, Germany
}

\begin{abstract}
The first part of the paper describes different concepts for micro production. The potential of miniaturised size adapted robots is pointed out based on their flexibility. Flexibility thereby is discussed in a detailed way that leads to two different ways of robot integration. The second part of the paper deals with the desktop factory concept. Beginning with a short state of the art for desktop factories, the preconditions for future concepts are discussed. Finally, with regard to a module for a desktop factory, the miniaturised precision robot Parvus, a micro gripper, a gripper changer and a robot control are presented.
\end{abstract}

Keywords desktop factory, flexibility, miniaturised robot, micro gripper, gripper changer, compact robot control

\section{Introduction}

Today, a trend of miniaturisation with regard to product development in several industrial sectors can be observed. Based on the Nexus III market study [1], it can be assumed that the market of millimeter-sized MST-products will grow by $16 \%$ per year. However, the gap between the dimensions and costs of the products and the production systems used is increasing. Assembly lines and clean rooms for millimeter-sized products often measure some tens of meters and are mostly too expensive for small- and medium-sized businesses. Therefore, many micro-products are assembled by hand, which causes high assembly costs that amount to $20 \%$ to $80 \%$ of the total production costs [2].

\section{Potentials for miniaturised robots in micro production systems}

In recent years, the reduction of size and costs of micro production systems has been widely discussed in various papers. Most of these concepts relate to one of the two general groups explained in the following. 
The first group consists of piezo driven, small walking micro robots and handling machines. These autonomous robots are suitable for positioning small objects such as the MINIMAN of Fatikow [3], a handling device for samples in a scanning electron microscope. On the one hand, these micro robots are very promising for new trends such as nano assembly. On the other hand, by using autonomous robots difficulties occur with coordination and interaction of these robots, movement on rough surfaces and energy supply.

The second group describes cost-efficient, size adapted handling devices, which fill the gap between piezo driven, small walking micro robots and conventional robots. A possible solution for this strategy is to find out the highest degree of miniaturisation of conventional robot technology, using innovative, miniaturised machine parts. With these size adapted handling devices, in the range of several centimeters to a few decimeters, easily scalable and highly flexible production technology can be achieved.

In the following, the potentials of flexibility of size adapted production machines will be discussed in a general view. First of all, flexibility can be subdivided into flexibility of function, flexibility of production volume, flexibility of placement and flexibility of property.

- Flexibility of function

Compared to conventional industrial robots, miniaturised robots can nowadays be equipped with a similar range of functionalities (e.g. degrees of freedom, sensors and tools). The combination of such miniaturised machines with freely programmable control systems, miniaturised drive systems and micro grippers can lead to the development of a micro production system with a high range of functionalities and motion-sequences.

- Flexibility of production volume

Less required space for miniaturised production machines makes it possible to replace a conventional robot by several miniaturized robots with increased productivity with regard to space. These concepts, known as the desktop factory concepts, increase the availability and the production volume. Hence, the manufacturer is more flexible in the number and variety of produced pieces.

- Flexibility of placement

Miniaturised production systems with a high density of functionality are flexible regarding their location. They can be placed in conventional clean rooms as well as in local clean room cells. Furthermore, companies profit from a high flexibility of placement with regard to the development of processes as well as the expansion and relocation of the company.

- Flexibility of property

Most conventional production systems are not sufficient for future applications. For most companies, a complete substitution of these production systems is impossible, as the newly acquired expensive systems have to be paid off. Thanks to 
miniaturised production machines, already existing larger production systems can be equipped with extended functionalities. Due to the smaller amount of space, miniaturised robots can be integrated into larger machines. The symbiosis of conventional technology and micro technology leads to improved flexible properties.

Based on the aforementioned assumptions, several of the current problems in micro assembly or the semiconductor industry can be solved by integrating a miniaturised robot pursuing two different strategies (Fig. 1):

a) As a component for miniaturised production systems such as visionary desktop factories, e.g. in micro production or micro assembly industry.

b) As a miniaturised production machine integrated into a conventional bigger machine, e.g. in testing machines for conductor boards.

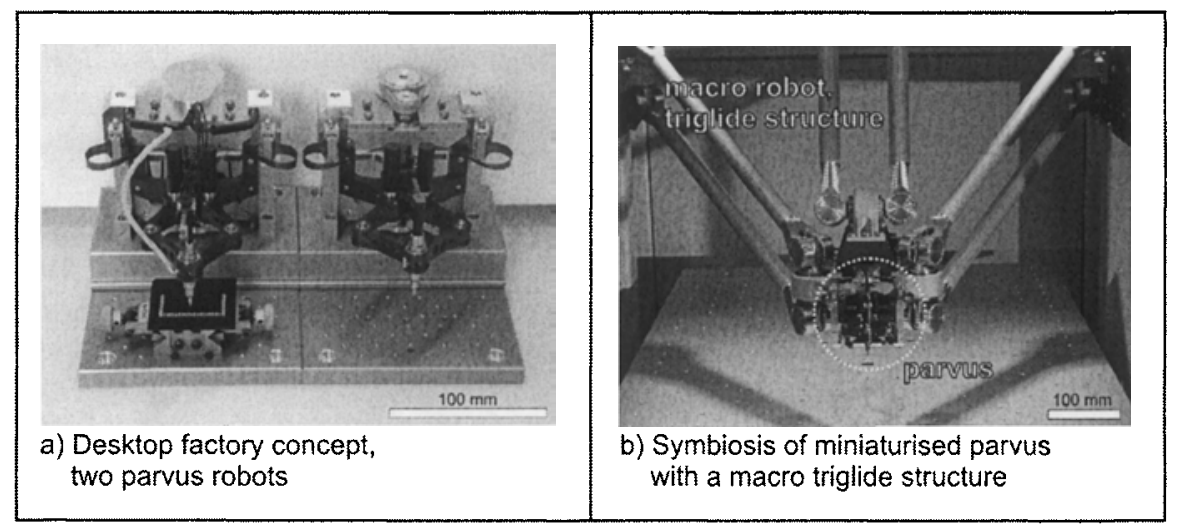

Fig. 1. Two strategies of system integration for the miniaturized robot Parvus

In the following, the paper will only deal with the aforementioned strategy (a) the integration of miniaturised handling devices into a visionary desktop factory.

\section{The modular Desktop Factory}

As for visionary desktop factories, it is necessary to develop highly modular systems by playing on the potentials of size adapted flexible handling systems, as presented in the previous chapter. Therefore, miniaturised components and handling devices with high flexibility of placement have to be developed. In addition, Breguet et al. [4] proclaimed in their paper Toward the Personal Factory that personal desktop factories should not be all-purpose but highly modular systems. In conventional automation technology, examples of modular production cells such as the system of IMSTec [5] can be found. However, there are only a few examples in 
research and industry of concepts for modular desktop factories. The concept of assembly modules mounted around a fixed platform is followed up in research projects by Gaugel et al. [6] and Rochdi et al. [7] and by the industrial manufacturer MiLaSys [8]. Many other concepts follow up the idea of a fixed production cell equipped with a main handling device and several subsystems, such as e.g. Uusitalo et al. [9] in research and Klocke Nanotechnik [10] as a manufacturer. In particular, these concepts and the aforementioned system of IMSTec point out that the size of the whole production system is limited by the size of the conventional precision robot used. These miniaturised production systems obviously require highminiaturised conventional precision robots and a miniaturised environment such as the concepts for modular Microboxes with the miniaturised precision robot PocketDelta of EPFL and HTI-Biel, Switzerland [11], [12].

Motivated by the aforementioned necessity of miniaturised components the Institute of Machine Tools and Production Technology (IWF) of the Technical University Braunschweig worked in cooperation with Micromotion $G m b H$ to develop a completely miniaturised precision robot with micro motors, micro encoders and high precise Micro Harmonic Drive gears. Furthermore, in cooperation with other institutes the environment for the robot will also become miniaturised.

\subsection{The functional model Parvus}

The challenge of the functional model Parvus was to develop a miniaturised precision industrial robot with the full functional range of larger models.

The robot consists of a typical parallel structure, driven by Micro Harmonic Drive [13] gears combined with Maxon electrical motors. This plane parallel structure offers two translational DOF in the $x-y$-plane. The $z$-axis is integrated as a serial axis in the base frame of the robot. The easy handling of the whole plane parallel structure driven in z-direction is possible because of its minimised drive components and light aluminum alloy structure. The rotational hand axis $\Psi$ was designed as a hollow rotational axis as the Tool Center Point (TCP) of the parallel structure. This allows media such as a vacuum to be passed along the hand axis. This axis, with a diameter of $2.5 \mathrm{~mm}$, can be equipped with several vacuum grippers. Further details are given by the technical specifications in Table 1.

The development of the Parvus, its fundamentals, the miniaturised drive systems and the robot design approaches were already described in several previous papers [14], [15]. 


\begin{tabular}{|c|c|c|}
\hline Criterion & Value & Unit \\
\hline Workspace (xy, absolute) & 4658 & $\mathrm{~mm}^{2}$ \\
\hline Workspace (max. cubical) & $60 \times 45 \times 20$ & $\mathrm{~mm} 3$ \\
\hline Footprint & $100 \times 53$ & $\mathrm{~mm}^{2}$ \\
\hline Robot cell & $130 \times 170$ & $\mathrm{~mm} 2$ \\
\hline Resolution max. (xy-plane) & $<1$ & $\mu \mathrm{m}$ \\
\hline Repeatability (best, worst) & $5.9,14.1$ & $\mu \mathrm{m}$ \\
\hline Linear speed & $>100$ & $\mathrm{~mm} / \mathrm{s}$ \\
\hline Rotational speed ( $\Psi$ axis) & $187^{*} / 60^{* *}$ & $\mathrm{rpm}$ \\
\hline Angular resolution ( $\Psi$ axis) & $0.022 * / 0.007^{* *}$ & $\circ$ \\
\hline $\begin{array}{l}\text { Payload } \\
*_{\text {ratio } 160: 1 / * * \text { ratio } 500: 1}\end{array}$ & 50 & $\mathrm{~g}$ \\
\hline
\end{tabular}

Table 1. Technical specifications of the first prototype

\subsubsection{Pick and Place applications with the Parvus}

For demonstration applications, the robot is equipped with a standard vacuum gripper (Fig. 2) to pick and place glass balls with a diameter of about $1.5 \mathrm{~mm}$.

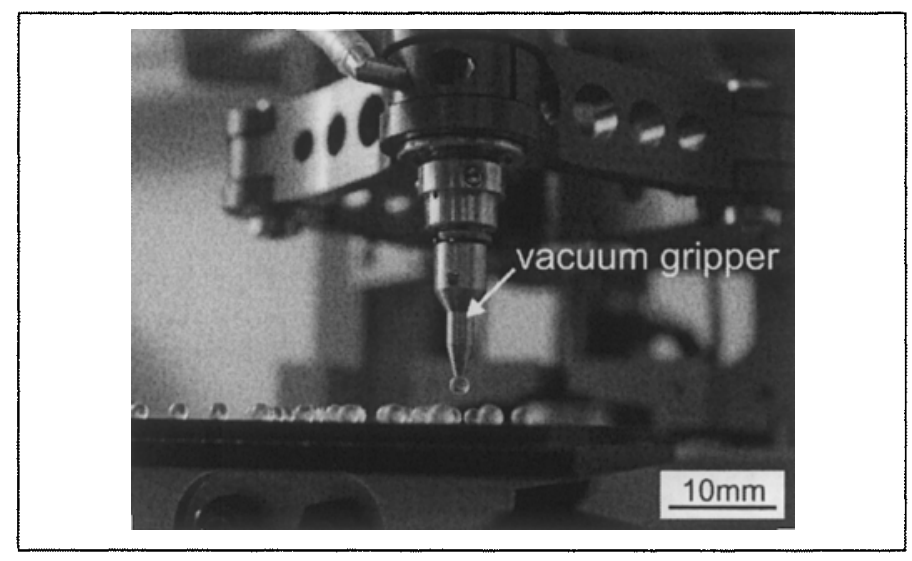

Fig. 2. Pick-and-place application of glass balls ( $(1.5 \mathrm{~mm})$ with Parvus

For gripping much smaller objects, a recently developed pneumatic micro gripper driven by a single channel for vacuum and pressure was integrated into the hand axis of the Parvus. The Institute for Microtechnology (IMT) of the Technical University Braunschweig developed this two-jaw micro gripper based on a micro pneumatic actuator manufactured in micro technology [16]. In cooperation between 
the $I M T$ and the $I W F$ the micro gripper was adapted for the Parvus. Experiments showed that it is possible to grip small ruby balls with $200 \mu \mathrm{m}$ in diameter (Fig. 3).

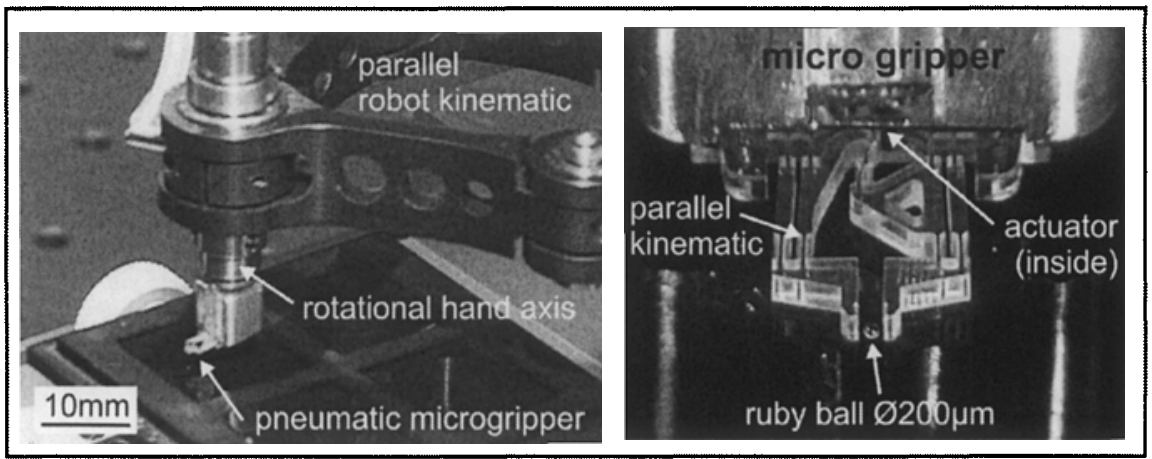

Fig. 3. Parvus equipped with a pneumatic micro gripper

To enable different flexible pick-and-place applications the Parvus will be equipped with a miniaturised tool changing station. The basic design of the tool changer consists of a rotating wheel with six tool seats. The different grippers can be disconnected and connected with the Parvus by a pneumatic working principle. Figure 4 shows the conceptual design of the gripper changing station, which is actually under construction.

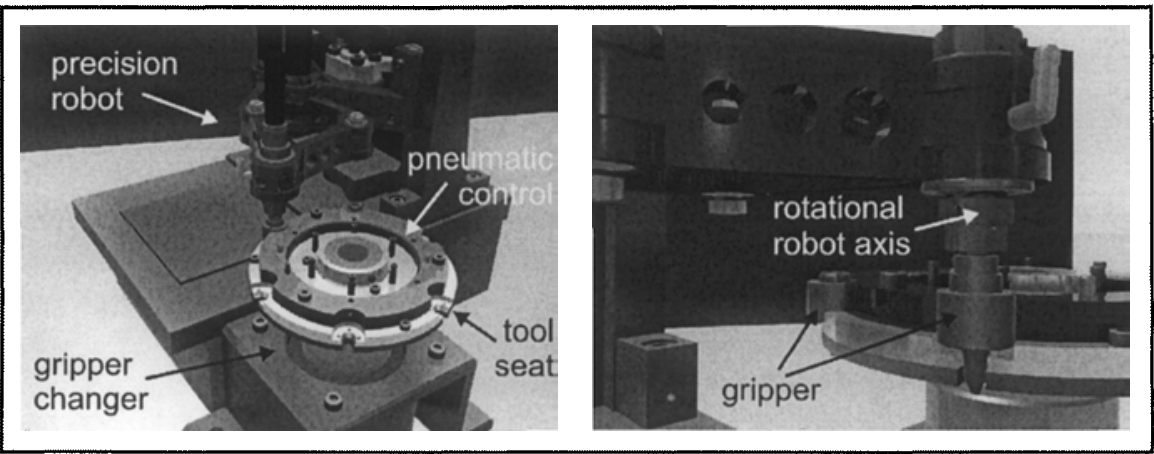

Fig. 4. Concept for pneumatic gripper changing station for the Parvus 


\subsubsection{Compact industrial robot control}

The first robot control for the Parvus was developed on a rapid prototyping system dSPACE in Matlab Simulink. To prepare a robot for the desktop factory concept, a compact industrial robot control is necessary. In cooperation with the company $B \& R$ [17] the Parvus recently was equipped with a PC based $1 / O$ System using a Celeron 650 processor. This system enables different task classes to run simultaneously. The transformations of the robot drives $q$ and the world coordinates $\rho$ can be calculated in real time. The central unit can be easily upgraded and operate with several $\mathrm{I} / \mathrm{O}$ modules and controllers connected with the robot drives and sensors or for communication with a superior field bus. By a VNC-Viewer, a graphical CNC Interface running on any PC connected via TCP/IP to the control system, the robot can be operated.

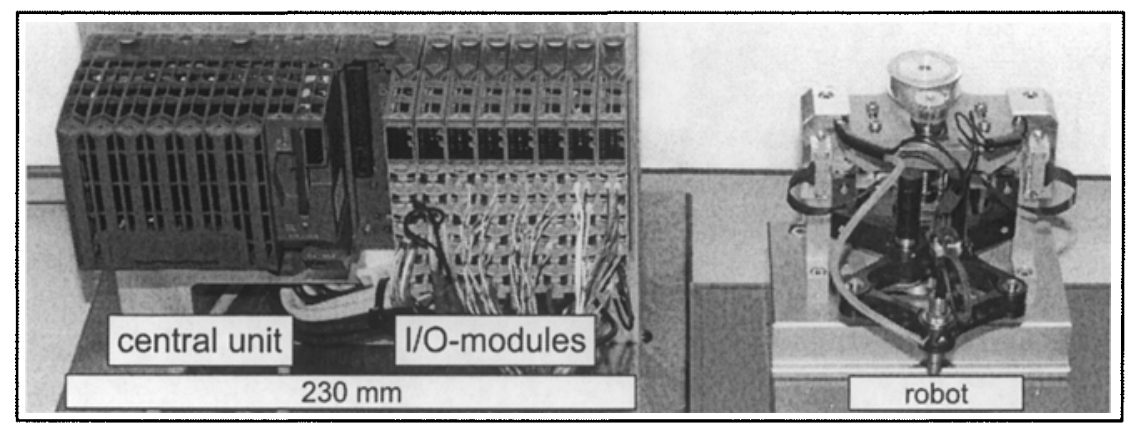

Fig. 5. Compact robot control of the Parvus

\section{Conclusion}

The paper points out that flexible desktop factories necessitate highly modular systems which have to be entirely miniaturised. Therefore, the development of such desktop factories needs a lot of technical expertise in several disciplines. The $I W F$ researches for miniaturized handling devices in cooperation with institutes of the Collaborative Research Center 516 and industrial partners. A result of such interdisciplinary research is the miniaturized precision robot Parvus equipped with micro gears, a micro gripper and gripper changer as a possible module for a desktop factory.

To achieve a highly modular desktop factory it is necessary to solve further challenges concerning the size and accuracy of many other handling devices. For instance, precise and miniaturised feeding systems or miniaturised magazines have to be developed in the future. 


\section{References}

[1] Wicht, H.; Bouchaud, J.: NEXUS Market Analysis for MEMS and Microsystems III 2005-2009. In: MST-news, Verlag VDI/VDE Innovation+Technik GmbH, Vol. 5, pp.33-34, 2005

[2] Koelemeijer, S.; Jacot J.: Cost Efficient Assembly of Microsystems. In: MST-news, Verlag VDI/VDE Innovation + Technik GmbH, Vol. 1, pp. 30-32, 1999

[3] Fatikow, S.: Miniman. In: Mikroroboter und Mikromontage, pp.277, ISBN 3-51906264-x, Teubner Verlag, Stuttgart - Leipzig, 2000

[4] Breguet, J.-M.; Bergander, A.: Toward the Personal Factory?. In: Proc. of SPIE, Microrobotics and Microassembly III, Vol. 4568, pp. 293-303, 2001

[5] IMSTec. http://www.imstec.de, 08.11.2006

[6] Gaugel, T.; Bengel, M.; Malthan, D.: Building a Mini-Assembly System from a Technology Construction Kit. In: Proc. of Intern. Precision Assembly Seminar (IPAS'2003), Bad Hofgastein, Austria, pp. 137-142, 2003

[7] Rochdi, K.; Haddab, Y.; Dembélé, S.; Chaillet, N.: A Microassembly Workcell. Proc. of Intern. Precision Assembly Seminar (IPAS' 2003), Bad Hofgastein, Austria, 2003

[8] MiLaSys technologies GmbH. http://www.milasys.de, 08.11.2006

[9] Uusitalo, J. J,; Viinikainen, H.; Heikkilä, R.: Mini assembly cell for the assembly of mini-sized planetary gearheads. In: Journal of Assembly Automation, Vol. 24/1, pp. 94101,2004

[10] Klocke, V.; Gesang, T.: Nanorobotics for micro production technology.

In: Proc. SPIE Conference Photonics Fabrication Europe, Brugge, Belgium, Vol. 4943, pp. 132-141, Oktober 2002

[11] Codourey, A.; Perroud, S.; Mussard; Y.: Miniature Reconfigurable assembly Line for small Products. In: Proc. of the Third Intern. Precision Assembly Seminar (IPAS'2006), Bad Hofgastein, Austria, 19-21 February 2006, S. Ratchev (Edt.), ISBN 0-387-31276-5, pp. 193-200, 2006

[12] Verettas, I.; Codourey, A., Clavel, R.: "Pocket Factory": Concept of Miniaturized Modular Cleanrooms. In: Ist Topical Meeting of Desktop MEMS and Nanofactories (TMMF2005), Tsukuba, JP, October 17-19, 2005

[13] Slatter, R.; Degen, R; Burisch, A.: Micro-Mechatronic Actuators for Desktop Factory Applications. In: Proc. of Intern. Symposium on Robotics ISR/Robotik 2006 München, pp. 137, VDI Wissensforum IWB GmbH, Düsseldorf, ISBN 3-18-091956-6, 2006

[14] Burisch, A.; Wrege, J.; Soetebier, S.; Raatz, A.; Hesselbach, J.; Slatter, R.: "Parvus" A Micro-Parallel-SCARA Robot for Desktop Assembly Lines. In: Proc. of the Third Intern. Precision Assembly Seminar (IPAS'2006), Bad Hofgastein, Austria, 19-21 February 2006, S. Ratchev (Edt.), ISBN 0-387-31276-5, pp. 65-74, 2006

[15] Burisch, A.; Wrege, J.; Raatz, A.; Hesselbach, J.; Degen, R.: PARVUS - miniaturised robot for improved flexibility in micro production. In: Journal of Assembly Automation, Emerald, Vol. 27/1, pp. 65-73, ISSN: 0144-5154, 2007

[16] Bütefisch, S.; Brand, U.; Leester-Schädel, M.; Hoxhold, B.; Büttgenbach, S.: Characterisation of Pneumatic and SMA Micro-Actuators with Short Response Times and Large Exerted Forces and Deflections. In: Proc. of Actuator 2006, Bremen, Germany, pp.483-486, 2006

[17] B\&R Industrie-Elektronik GmbH. http://www.br-automation.com, 20.06.2007 